\title{
New Technologies and Nursing: Use and Perception of Primary Healthcare Nurses About Electronic Health Record in Catalonia, Spain
}

\author{
Jordi Galimany-Masclans, B.S., Eva Garrido-Aguilar, B.S., \\ $M^{a}$ Rosa Girbau-García, Ph.D., Teresa Lluch-Canut, Ph.D., \\ and Nuria Fabrellas-Padrés, B.S.
}

School of Nursing, University of Barcelona, Barcelona, Spain.

\begin{abstract}
This study was aimed to analyze and assess the use and perception of electronic health records (EHRs) by nurses. The study sample included 113 nurses from different shifts of primary health facilities in Catalonia, Spain, devoted to adult as well as pediatric outpatients using EHRs throughout the year 2010. A majority of the sample (87.5\%) were women and $12.5 \%$ were men. The average age was 44.27 years and the average time working in primary healthcare was 47.15 months. A majority (80.4\%) received specific training on the use of the EHR and $19.6 \%$ did not. The use of the application required side technical support (mean: 3.42 ) and it is considered necessary to learn more about the performance of the application (mean: 3.50). The relationship between the average ratings that nurses have about the EHR and age shows that there is no statistically significant linear relationship $(\mathrm{r}=$ -0.002 , $\mathrm{p}$-value $=0.984)$. As to how long they have used the EHRs, there are significant differences $(\mathrm{r}=-0.304$, $\mathrm{p}$-value $=0.00)$, so the more time the nurse takes using the EHR, the greater degree of satisfaction is shown. In addition, there are significant differences between nurses' perceptions regarding the EHR and gender $(\mathrm{t}=$ -0.421 , p-value $=0.675$ ). Nurses assessed as positive the contribution of the EHRs in their nursing care day work (average score: 2.55/5). Considering that the usability of the EHR device is assessed as satisfactory, the results of the perception of nurses show that we must also take into account the training and emphasize the need for a side technical support in the implementation process of the EHR. Doing so, the positive perception that nurses have in regard to information and communication technology in general and with respect to the EHR in particular may be increased.
\end{abstract}

Key words: medical records, e-health, telemedicine

\section{Introduction}

$\mathrm{H}$

ealth systems in many countries are integrating information and communication technology (ICT) tools in healthcare. Recently, the importance of ICT to achieve efficient and sustainable healthcare was highlighted dur- ing the E-health Week 2010, held in Barcelona, Spain. ${ }^{1}$ Spain is developing processes based on the incorporation of ICT in the health sector with a focus on the implementation of the electronic health record (EHR) in the primary healthcare (PHC) in the Catalonia region of Spain. Catalonia is characterized by a healthcare system with various providers and with certain peculiarities that have determined the implementation of the EHR. ${ }^{2}$

The purpose of this research was to explore the nurse's perceptions regarding the EHR in the PHC level as the first step in the health system. We thought that necessary to open a new perspective in the integration of all patient health information. The EHR is the basis of the information register that allows access to patient health data at any time, anywhere. The role of the nurse is highly relevant, because she records and manages health information and patient data.

The medical record (MR) is defined a longitudinal recording wherein you store the data generated in the relationship between a patient and a health institution. This registry collects data from birth to death, related to either healthcare or prevention. It details, in addition to the clinical data relating to situations of health or disease, personal history, heredity, habit, physical constitution, psychology, their environment, and the etiology of diseases. Among the documents that make up the MR are those that reflect the considerations, observations, and clinical judgments of health professionals, so that these documents can be used to evaluate their performance. The MR is an instrument that is also used as a source of information for epidemiological-clinical research and analysis of management processes to improve the quality of care. The EHR is the electronic record of the MR that can be consulted at any point of care facility. ${ }^{3}$

There are different models of EHR, some characterized by focusing on records to guide the work of healthcare professionals and others are designed by taking into account the needs of healthcare institutions. There are also those that are characterized by a record of events, patient-centered care from birth to death, and have become an indispensable tool for coordination, as it ensures the interaction between all levels of system support and the continuity of care provided by health professionals. ${ }^{4}$

At the PHC setting, the EHR is a fundamental information resource. It is the most important document that houses most of the information handled by professionals and health managers at this level of care. Its aim is to sort the information to provide care to patients, families, and communities and promote research and evaluation of services. In this way, the EHR allows us to offer individualized care, facilitates the coordination of 
Table 1. Sample Demographic Characteristics

\begin{tabular}{|c|c|}
\hline \multicolumn{2}{|l|}{ Age } \\
\hline Min. & 26 \\
\hline Max. & 64 \\
\hline Mean & 44.27 \\
\hline SD & 10 \\
\hline \multicolumn{2}{|l|}{ Sex } \\
\hline Male & $12.5 \%$ \\
\hline Female & $87.5 \%$ \\
\hline \multicolumn{2}{|c|}{ Specific training } \\
\hline None & $19.6 \%$ \\
\hline Yes & $80.4 \%$ \\
\hline \multicolumn{2}{|c|}{ Time working with EHR } \\
\hline Min. & 1 \\
\hline Max. & 120 \\
\hline Mean & 47.1 \\
\hline SD & 29.6 \\
\hline
\end{tabular}

$E H R$, electronic health record.

professionals from different services, and makes quality assessment possible.

The recording of the activities and nursing care reflect the health needs of the patient and the assistance provided by the nurse. Currently, the PHC nurses develop a key role in community health, because they need access to this information to make decisions and act as a true agent of the patient's health. ${ }^{5}$ The record of the care is part of the functions that allow nurses to focus on their work. At the same time it also serves to study and evaluate, generating critical appraisal elements that can improve nursing care. ${ }^{6}$ Nursing documentation can become a mechanism for improvement and innovation of nursing care in the PHC, all set in a more democratic, more patient-centered way, and for sharing information among all health professionals involved in the patient's health. ${ }^{7,8}$

We need a willing and positive motivational environment to adopt these new tools, both in the initial phase of its implementation and in the subsequent phases to be sure to provide training and support to professionals who handle the EHR. ${ }^{9,10}$ It should be kept in mind that these technological improvements add up to a health situation that is characterized by an aging population, increasing numbers of people with chronic and multiple diseases, who require highly complex care. This causes a growing demand of the healthcare system users, causing high pressure on the professionals.

As a part of ICT, a well-designed EHR can improve continuity of care. Also, it is important to consider that results can be transferred to other care areas when future EHR devices become implemented. Further, the perception of the nurse shall help toward the improvement of the EHR. The evaluation of the EHR implementation in health systems in countries where it develops is essential for success.

\section{Materials and Methods}

The aims of this research were the following points:

1. To analyze the use of EHRs by nurses and assess their perception of it;

2. To assess whether the EHR facilitates coordination and knowledge of the patient's care route;

3. To analyze the nurses' perceptions regarding the usability and the user's opinion regarding the structure, degree of integration, and coherence of application. This evaluation can also include how they feel about it and the adequacy of the EHR for the register of nursing care provided to patients in the PHC;

4. To explore the sociodemographic profile of nurses who form the study sample;

5. To know the specific training received by nurses to use the EHR; and

6. To analyze the existence of relationships between nurses' perceptions regarding the EHR and the demographic variable age and also whether there are gender differences.

\section{DESIGN}

A descriptive cross-sectional study was carried out.

\section{SAMPLE/PARTICIPANTS}

The study sample consisted of 113 nurses who worked different shifts in support of adult and pediatric visits in PHC teams in Catalonia that used the EHR in 2010. Inclusion criteria were nurses who had used the EHR at least during 6 months before the data collection and wanted to participate in the study. Exclusion criteria were nurses in internship or in international mobility programs. The sampling technique has been convenient.

To carry out this project, permission from official institutions was requested and approved by the bioethics committee of the University of Barcelona. The nurses participating in the study were guaranteed confidentiality and anonymity as well as keeping the data collected after the end of the study.

\section{DATA COLLECTION METHODS}

A specifically designed questionnaire consisting of four parts was developed. The first part refers to continuity of care; the second to usability (adapting the questionnaire System Usability Scale, validated by Digital Equipment Corporation 1986); a third includes the recording of information in the application; and the fourth part contains the demographic variables. A 5-point Likert scale $(1=$ strongly agree, 2 =agree to some extent, $3=$ neither 
agree nor disagree, $4=$ disagree to some extent, and $5=$ strongly disagree) was used. Before the general survey was conducted, a pilot test was carried out, in which the questionnaire was administered to a sample between 15 and 20 nurses, to identify potential difficulties in completing the questionnaire response and to minimize them.

\section{DATA ANALYSIS}

To describe the characteristics that reflect the individuals who are part of the study, a descriptive analysis, including frequency tables, measures of central tendency, dispersion and graphs based on their suitability to the type of variable, possible degree of asymmetry, and presence of outliers, was performed.

To analyze the degree of linear relationship between quantitative variables and to see whether this can be considered significant, we used the linear correlation coefficient of Pearson. Finally, to test the correlation between the average rating with the nurses about the advantages of the application EHR and sex, $t$-test was used for comparison of means test for independent data. To perform statistical analysis, PASS version 17 was used.

\section{Results}

\section{NURSES SAMPLE CHARACTERISTICS}

The study was based on a total of 113 nurses. About 87.5\% were women and $12.5 \%$ men. The average age was 44.27 years; the average time working in PHC was 47.15 months. The $80.4 \%$ of the nurses of the study received specific training to use the EHR but 19.6\% did not (Table 1).

\section{PSYCHOMETRIC QUALITIES OF NURSES' PERCEPTION ABOUT EHR}

The coefficients of internal consistence (Cronbach's $\alpha$ ) of the measurement scales perception about EHR were satisfactory (0.875).

\section{NURSES' PERCEPTION ABOUT EHR}

The results serve to confirm the positive perception of nurses with regard to ICT in general and with respect to the EHR in particular. The average ratings on the perception that nurses make of the EHR show a fairly positive perception (mean $=2.55, \mathrm{SD}=0.49$ ). This perception is based on the fact that the EHR allows nurses to provide and exchange information, thus getting to know the clinical pathways of patient care in reference to their continuity of care.

The analysis of the relationship between the average ratings that nurses have about the EHR and age shows that there is no statistically significant linear relationship $(r=-0.002, p$-value $=0.984)$. As to how long they have used the EHR, there are significant differences ( $r=-0.304, p$-value $=0.00$ ), so the more time the nurse takes using the EHR, the greater degree of satisfaction is shown. Significant differences have been detected between nurses' perceptions regarding the EHR and gender $(t=-0.421, p$-value $=0.675)($ Table 2$)$.
Table 2. Relationship Between Mean Age, Time Using the Application, and Gender (Test Statistic and Significance Level)

Age

\begin{tabular}{l|l|l}
\hline & \multicolumn{2}{l}{ Pearson correlation coefficient } \\
\hline & $r=-0.002$ & $p$-value 0.984 \\
\hline Time & \multicolumn{2}{|l}{ Pearson correlation coefficient } \\
\hline & $r=-0.343$ & $p$-value 0.00 \\
\hline Gender & \multicolumn{2}{|l}{} \\
\hline & Student's $t$-test & $p$-value $=0.675$ \\
\hline & $t=0.421$ &
\end{tabular}

\section{CONTINUITY OF CARE}

The average ratings are positive in those items that examine the continuity of care (were 1.66 and 2.56 out of 5), showing that nurses agree that the EHR provides continuity of care (Table 3).

\section{USABILITY}

The mean scores indicate that, in general, the EHR has enough usability (were 1.97 and 3.90 out of 5). Several reasons that stress the improvement of EHR are, on the one hand, that a side technical support is required (mean $=3.42$ ), and on the other hand, it is necessary to learn more things to become keen in the application $($ mean $=3.50)$ (Table 3).

\section{Discussion}

Evaluating EHR devices is not an easy task, because different settings coexist. Some studies assess the attitude and satisfaction of nurses compared to devices of EHR but fewer have explored the characteristics of the applications in themselves, their social, cultural, and organizational values, as well as those relevant elements that make up the EHR in relation to the nursing practice. ${ }^{11}$ It seems clear that the structured recording of data to become an EHR provides for a significant improvement of nursing care to benefit patients but also it is an important tool for quality of care evaluations. ${ }^{7}$ It is fully accepted that the computerized record is a positive step for the patient's healthcare. ${ }^{6}$

\section{Conclusions}

In conclusion, in a health scenario characterized by increased spending, declining resources, and the need to achieve organizational efficiency by healthcare institutions, ICT in general and the EHR in particular are emerging as essential tools for achieving the sustainability of health systems. However, deep organizational 


\begin{tabular}{|c|c|c|c|c|}
\hline ITEMS & MIN. & MAX. & MEAN & SD \\
\hline Facilitates coordination between healthcare levels & 1 & 5 & 2.28 & 1.03 \\
\hline Lets you know the trajectory of care (traceability) of the patient & 1 & 5 & 2.19 & 0.98 \\
\hline Let the nurse know all the medical team caring for the patient & 1 & 4 & 2.08 & 0.92 \\
\hline Lets meet basic health data & 1 & 5 & 1.66 & 0.92 \\
\hline Facilitates knowledge of the patient's health problems & 1 & 5 & 1.79 & 0.94 \\
\hline To exchange information with the primary care team & 1 & 5 & 1.98 & 0.97 \\
\hline Maintains the confidentiality of records & 1 & 5 & 2.50 & 1.11 \\
\hline Collect all the information the nurse needs & 1 & 5 & 2.59 & 0.94 \\
\hline Allows better individualized nursing care & 1 & 5 & 2.56 & 0.86 \\
\hline Helps refer patients satisfaction with primary care team & 1 & 5 & 3.05 & 0.92 \\
\hline In my own opinion the use of the software domain & 1 & 4 & 2.40 & 0.84 \\
\hline I think the application is absolutely unnecessary & 1 & 5 & 1.97 & 1.17 \\
\hline In my opinion the application is easy to use & 1 & 5 & 2.80 & 0.92 \\
\hline I think that to use the application you need support & 1 & 5 & 3.42 & 1.20 \\
\hline In my view, several features are well integrated into the application & 1 & 5 & 2.35 & 0.79 \\
\hline I think the application has too many inconsistencies & 1 & 5 & 2.85 & 0.88 \\
\hline I think most people have learned to use the application quickly & 1 & 5 & 2.95 & 1.01 \\
\hline In my own opinion the application is very cumbersome & 1 & 5 & 2.81 & 0.98 \\
\hline I feel very confident when I use the application & 1 & 5 & 2.68 & 0.96 \\
\hline $\begin{array}{l}\text { I think I need to learn many more things to get maximum } \\
\text { performance at the application }\end{array}$ & 1 & 5 & 3.90 & 1.11 \\
\hline The application is suitable to record care & 1 & 5 & 2.50 & 1 \\
\hline Conditional registration of the care provided & 1 & 4 & 2.39 & 0.90 \\
\hline It covers all the nursing care performed & 1 & 5 & 2.99 & 1.03 \\
\hline
\end{tabular}

changes are needed to adapt to new technological environment and to provide quality care to the community.

The future research regarding this investigation refers, first, to replicate with other samples the analysis to confirm whether the factors obtained are maintained and, second, to conduct this research in other levels of care and other health professionals.

The main limitation of the study was the use of a convenient sample, and therefore, results cannot be extrapolated to the rest of the population. In addition, as the research has been carried out only in the level of care in PHC, one cannot compare the results with the hospital or other social health facilities.

\section{Disclosure Statement}

No competing financial interests exist.

\section{REFERENCES}

1. Jha AK, Doolan D, Grandt D, Scott T, Bates DW. The use of health information technology in seven nations. Int J Med Inf 2008;77:848-854.

2. Marimon S, Rovira M, Acedo M, Nozal MA, Guanyabens J. Shared electronic health record in Catalonia, Spain. Med Clin 2010;134(Suppl 1):45-48.

3. Hayrinen K, Saranto K, Nykanen P. Definition, structure, content, use and impacts of electronic health records: A review of the research literature. Int J Med Inf 2008;77:291-304.

4. Tornvall $E$, Wilhelmsson $S$, Wahren LK. Electronic nursing documentation in primary health care. Scand J Caring Sci 2004;8:310-317.

5. Nic Philibin CA, Griffiths C, Byrne G, Horan P, Brady AM, Begley C. The role of the public health nurse in a changing society. $J$ Adv Nurs 2010;66: 743-752.

6. Muller-Staub M, Lavin MA, Needham I, van Achterberg T. Nursing diagnoses, interventions and outcomes-Application and impact on nursing practice: Systematic review. J Adv Nurs 2006;56:514-531. 
7. Saranto K, Kinnunen UM. Evaluating nursing documentationResearch designs and methods: Systematic review. J Adv Nurs 2009; 65:464-476.

8. Thompson $D$, Johnston $P$, Spurr $C$. The impact of electronic medical records on nursing efficiency. J Nurs Admin 2009;39:444-451.

9. Eley R, Fallon T, Soar J, Buikstra E, Hegney D. The status of training and education in information and computer technology of Australian nurses: A national survey. J Clin Nurs 2008;17:2758-2767.

10. Littlejohns P, Wyatt JC, Garvican L. Evaluating computerised health information systems: Hard lessons still to be learnt. $\mathrm{Br} \mathrm{Med} \mathrm{J} \mathrm{2003;}$ 326:860-863.

11. Delpierre C, Cuzin L, Fillaux J, Alvarez M, Massip P, Lang T. A systematic review of computer-based patient record systems and quality of care: More randomized clinical trials or a broader approach? Int J Qual Health Care 2004;16:407-416.
Address correspondence to: Jordi Galimany-Masclans, B.S. School of Nursing Department of Public Health, Mental Health, and Perinatal Nursing University of Barcelona Feixa LLarga Street, Office 313, 3rd Flr. 08907 L'Hospitalet de LLobregat Barcelona, Spain

E-mail: jordigalimany@ub.edu

Received: January 12, 2011 Revised: March 21, 2011

Accepted: March 21, 2011 
This article has been cited by:

1. Marie-Rachelle Narcisse, Thomas A. Kippenbrock, Ellen Odell, Bill Buron. 2013. Advanced Practice Nurses' Meaningful use of electronic health records. Applied Nursing Research . [CrossRef]

2. GENEVIEVE LEBLANC, MARIE-PIERRE GAGNON, DUNCAN SANDERSON. 2012. Determinants of Primary Care Nurses' Intention to Adopt an Electronic Health Record in Their Clinical Practice. CIN: Computers, Informatics, Nursing 30:9, 496-502. [CrossRef] 